\title{
INVESTIGATION INTO THE EFFECTIVENESS OF THE JLAB HIGH PRESSURE RINSE SYSTEM*
}

\author{
J. Mammosser", T. Rothgeb, T. Wang, A.T. Wu, Jefferson Lab, Newport News, VA 23606, USA
}

\section{Abstract}

As part of a study to reduce field emission in Superconducting radio frequency cavities, an investigation into the effectiveness of the Jefferson Lab's High Pressure Rinse (HPR) system is underway. This paper describes discoveries from this investigation, the procedural changes made during this investigation, current vertical test results and further plans for improvements and monitoring.

\section{CAVITY PERFORMANCE ISSUES}

After the vertical dewar qualifying tests on the South Linac 21 (SL21) cavity string, an effort was renewed to reduce field emission and improve cavity performance. Many of the cavities tested for the SL21 string were field emission limited. The average gradient for field emission onset during vertical tests of these cavities was 8.5 MV/m. Testing of these same cavities in the SL21 cryomodule showed better performance in both Q-value and gradient, with the average field emission onset gradient being $13 \mathrm{MV} / \mathrm{m}$. Early field emission onset in the vertical tests, led to the need to repeat many of the cavity qualification tests. The immediate focus for process improvement was on the HPR system and the Deionised (DI) water plant that supports it. The HPR represents the final cleaning step in our assembly process and understanding its effect on cavity performance may indicate avenues for further improvements.

\section{JLAB'S PRODUCTION HPR SYSTEM}

Jefferson Lab's production HPR system consists of a high-pressure pump (ceramic plunger style) pumping ultra pure DI water through a wand, a linear actuator for moving the wand, and a rotary table for rotation of the cavity. Typical cavity process parameters are :

$\begin{array}{ll}\text { Flow rate } & 18.9 \mathrm{1} / \mathrm{min}(5.0 \mathrm{gpm}) \\ \text { Wand velocity } & 0.3048 \mathrm{~m} / \mathrm{min}(12 \mathrm{in} / \mathrm{min}) \\ \text { Wand motion } & \text { Reciprocating } \\ \text { Rotational speed } & 1 \mathrm{rpm} \\ \text { Water pressure } & 8.27 \mathrm{mPa}(1200 \mathrm{psi}) \\ \text { Rinse duration } & \text { Typically } 1 \text { hour }\end{array}$

The spray wand has nine $0.4 \mathrm{~mm}(0.016$ ") nozzles located around the head of the wand. Three of the nozzles are pointed up at a $45^{\circ}$ angle, three are pointed down at a $45^{\circ}$ angle and the remaining three spray out horizontally. The nozzles are aligned vertically and spaced around the head $120^{\circ}$ apart. The HPR system is contained in a cabinet that is located in a Class 100 cleanroom.

A simulated pattern of the HPR spray impact path as mapped out on the SNS medium beta cavity cell surface,

*Work supported by United States Department of Energy under contract DE-AC05-84ER40150

\#mammosse@jlab.org. is shown in Figure 1. These simulated impact paths for

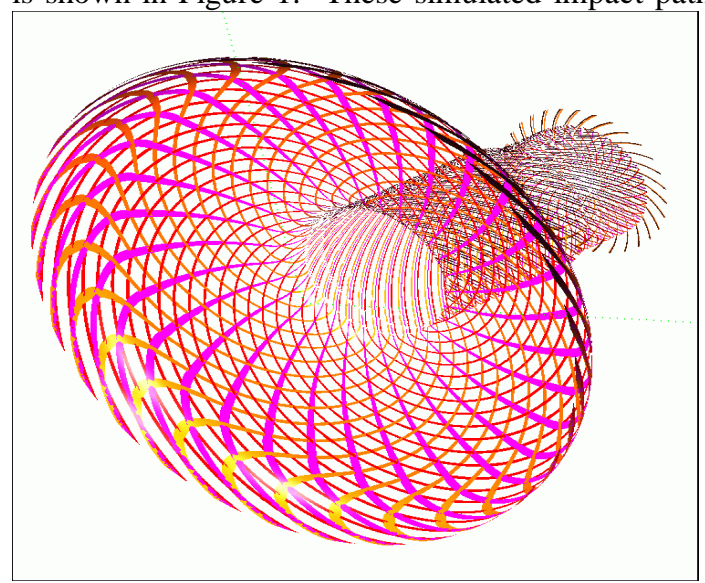

Figure 1: HPR spray impact path for 30 passes all 9 nozzles on an SNS medium beta cavity cell.

all 9 nozzles cover approximately $12 \%$ of the cavity surface per pass. From this pattern it is easy to deduce that the impact path of the water yields many areas of light coverage on the surface, which miss the direct force of the water stream.

\section{Analysis of Process DI Water Quality}

Water system quality was sampled prior to making any changes to the system in order to establish a baseline. Two sample locations were used, at the HPR outlet and after the final $0.1 ? \mathrm{~m}$ filter at the DI plant. The water was tested for bacteria, total oxidizable carbon (TOC), dissolved silica, total silica, anions, cations and 68 trace elements. Table I compares the results of the tests with the original pure water specifications and guidelines (from 1988) [1]. Only those results that did not meet the requirement are shown here. These data show that the number of particulates coming out of the HPR was much higher than that of the DI plant, and could be a significant contributor to poor cavity performance.

Along with the tests mentioned above, water samples were collected for Scanning Electron Microscopy (SEM) studies. The results of these tests showed bacteria as well as filter media particulates coming from the HPR system. The filter in the HPR was comprised of borosilicate glass with a $0.2 ? \mathrm{~m}$ pore size. It was removed and particulates from it were analysed. Two sampling ports were added to the HPR water path, one just before entering the cavity wand (inlet) and a second (drain) to collect rinse water draining from the cavity during processing. Samples were taken during SNS medium ? cavity HP rinses and these showed high particle counts on the inlet. Approximately 300 particulates were counted during a 20-minute sample and significantly fewer counts of 83 from the drain sample near the beginning of the run and 60 at the inlet, near the end of the run. Most of the elements identified were also identified in the filter media 
analysis .Figure 2 shows the relative amounts of analysed elements from the HPR filter.

The DI water plant filters were replaced and the plant was sanitized and flushed to kill and remove bacteria. Afterwards, a new $0.1 ? \mathrm{~m}$ membrane HPR filter was installed and a $1.5 \mathrm{l} / \mathrm{min}$ trickle flow of DI through the HPR system was added to reduce bacteria growth in the filter media and pump when the system was idle. A laser water particle counter was added at the HPR wand inlet sample location to monitor particulates during rinses. Figure 3 shows the water particle counts during a typical cavity HPR after the DI water system was sanitized.

Table I - HPR Specifications and Results

\begin{tabular}{|l|l|l|l|}
\hline & Limit [2] & HPR & $\begin{array}{l}\text { Final } \\
\text { Filter }\end{array}$ \\
\hline Bacteria & $1 \mathrm{cfu}$ & $>500$ & $*$ \\
\hline TOC & $5 \mathrm{ppb}$ & $*$ & $*$ \\
\hline $\begin{array}{l}\text { Dissolved } \\
\text { Silica }\end{array}$ & $1 \mathrm{ppb}$ & 16 & 17 \\
\hline Total Silica & $1 \mathrm{ppb}$ & 15 & 17 \\
\hline Chloride & $0.02 \mathrm{ppb}$ & 0.05 & 0.07 \\
\hline Sodium & $0.01 \mathrm{ppb}$ & 0.85 & 0.03 \\
\hline Potassium & $0.02 \mathrm{ppb}$ & 0.86 & $*$ \\
\hline Magnesium & $0.02 \mathrm{ppb}$ & 0.12 & $*$ \\
\hline Calcium & $0.02 \mathrm{ppb}$ & 0.42 & $*$ \\
\hline Barium & $0.001 \mathrm{ppb}$ & 0.18 & $*$ \\
\hline Boron & $0.05 \mathrm{ppb}$ & 4.0 & 4.4 \\
\hline Magnesium & $0.002 \mathrm{ppb}$ & 0.11 & $*$ \\
\hline Manganese & $0.002 \mathrm{ppb}$ & 0.006 & $*$ \\
\hline Nickel & $0.004 \mathrm{ppb}$ & 0.027 & $*$ \\
\hline Potassium & $0.1 \mathrm{ppb}$ & 0.6 & $*$ \\
\hline Rubidium & $0.001 \mathrm{ppb}$ & 0.003 & $*$ \\
\hline Silicon & $0.5 \mathrm{ppb}$ & 7.6 & 8.0 \\
\hline Sodium & $0.007 \mathrm{ppb}$ & 0.55 & 0.023 \\
\hline Strontium & $0.001 \mathrm{ppb}$ & 0.003 & $*$ \\
\hline Zinc & $0.005 \mathrm{ppb}$ & 0.74 & $*$ \\
\hline
\end{tabular}

* not detectable

\section{Particulate Collection and Analysis From Cavities}

Particulate samples were collected from cavities that showed heavy field emission during vertical tests and from vacuum piping and pumps on one of the production vertical test stands for comparison to water particulates collected. Cavity and vacuum system samples were collected using double sided carbon tape by blotting the end flange and beam-tube surfaces and bagging in clean nylon bags. Figure 4 shows analysis of the particulates found in an SNS medium beta cavity after a failed vertical test at the beginning of this investigation. Figure 5 shows the particulates collected from cavity JL009 after a failed vertical test. JL009 test was near the end of the SL21 qualification testing and before any changes to the DI water system.

Particulates were also collected from the vacuum system piping on the vertical test stand and the roughing pump was opened and samples collected and analysed. The particles in the cavity samples analysed showed were consistent with those elements found in the water and HPR analysis yet there were some that could not be explained, such as Au. In the vacuum system many particulates had collected in the lower portions of the vacuum system piping and consisted of many of the elements found in the DI water and HPR analysis. Many of the metals that make up the stand components, such as $\mathrm{Cu}, \mathrm{Fe}, \mathrm{Cr}$ and $\mathrm{Ni}$ were also found. From all the particulate analyses it became clear that silicon was present in large quantities in the water plant from both the HPR and in cavity samples.

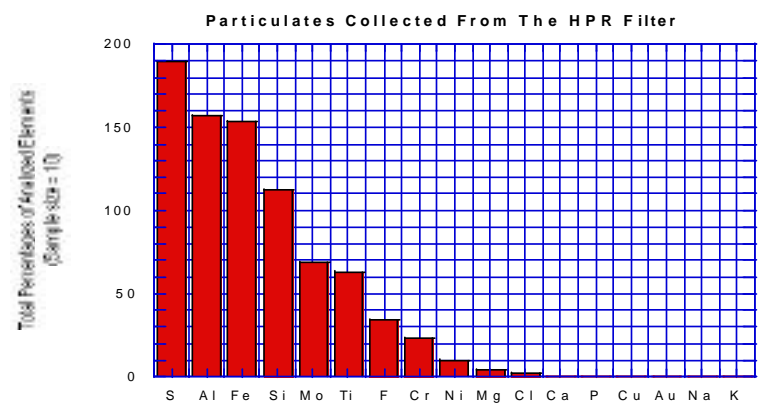

Figure 2. Relative population of HPR filter particulates by element.

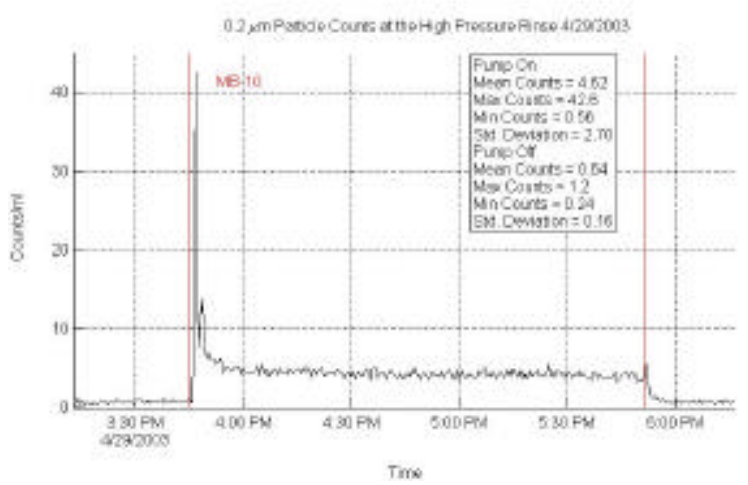

Figure 3. Counts of $0.2 ? \mathrm{~m}$ sized particles during a typical HPR

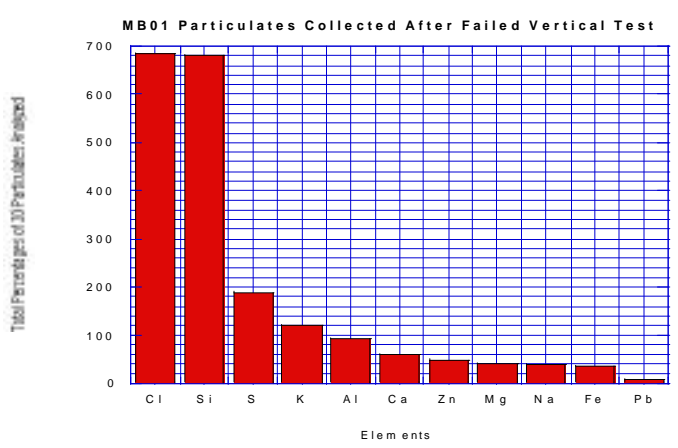

Figure 4. Particulates Collected From MB01 


\section{PROCESS PROCEDURAL CHANGES IMPLEMENTED}

One additional concern was that with only one hour of high pressure rinsing, that the cavity surfaces might not be cleaned well enough, even if the water system was improved. The problem with increasing the amount of high pressure rinsing was the DI water storage capacity and make-up rate, which were only 8000 litres and $81 / \mathrm{min}$, respectively. This allowed for only a single twohour high pressure rinse per day. A new reverse osmosis system was installed to provide a make up rate of $20 \mathrm{l} / \mathrm{min}$. Along with doubling the time for cavity rinsing, this allowed a second two-hour rinse cycle to be added for cavities after they had most of their test hardware assembled to the flanges. Only the bottom evacuation flange connection was not assembled for the second rinse cycle. This second cycle allowed the cavity and the test hardware to be cleaned in the same way, and to minimize the assembly steps needed for completion of the hermetic sealing of the cavity. The cavity is rinsed and dried vertically in the HPR cabinet overnight and the bottom flange blanked off for removal and assembly of the evacuation flange.

A study into the effect of field emission onset due to the location of particulates from the cavity drying position is also underway. As part of this study, four of the eight cavities for the Free Electron Laser (FEL) string were dried horizontally before vertical tests.

\section{COMPARISON OF FIELD EMISSION ONSET FOR SL21 AND FEL3 CAVITIES}

Upon the completion of the FEL3 vertical cavity qualification tests, it was apparent that field emission onset performance had improved. These cavities are the same shape and configuration as those for SL21. The only significant difference was changes to the processes used and to the facilities. Figure 6 shows that the average onset of field emission had increased by $4.3 \mathrm{MV} / \mathrm{m}$ for FEL3 cavities, but with a larger range. The last four cavities that were dried horizontally had the best performance, with an average field emission onset of $17.5 \mathrm{MV} / \mathrm{m}$, and a standard deviation of $1.75 \mathrm{MV} / \mathrm{m}$.

\section{CONCLUSION}

Many changes over the last year have been made to both procedures and processing facilities. Some improvements to performance are being observed from vertical test data. It is however difficult with the present limited statistics to determine which changes had the most significant impact on performance. Future plans are to continue analysis and monitoring of the DI and HPR systems and improve the surface coverage of cavities during high pressure rinsing by modifying the current programs, to come to a better understanding of the drying process, and to continue tracking vertical test cavity performance.

\section{ACKNOWLEDGEMENTS}

We would like to thank Jim Henry for modelling the HPR spray impact path.

\section{REFERENCES}

[1] T. Meltzer, High-Purity Water Preparation For The Semiconductor, Pharmaceutical and Power Industries (1997) p.19.

[2] S. Schoen Balazs Analytical Services report dated September 19, 2002.

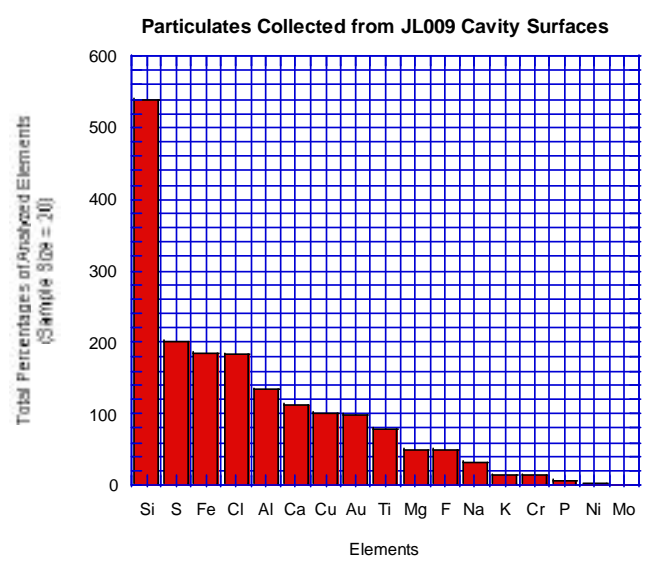

Figure 5. Particulates collected from JL009 after a failed vertical test.
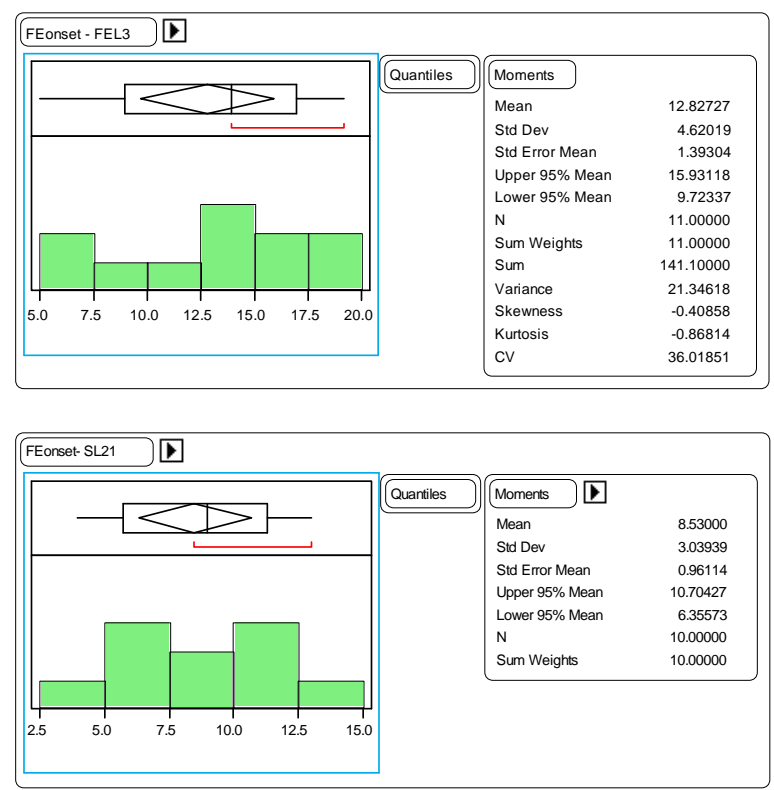

Figure 6. Vertical Test Field Emission Onset Comparison 